\title{
Recombinant human thrombopoietin combined with interleukin-2 improves the effects of chemosensitivity and thrombocytopenia on a basic gemcitabine and carboplatin combination therapy for non-small cell lung cancer in a nude mouse model
}

\author{
Yunhua Xu ${ }^{1 \#}$, Yan Pan $^{2 \#}$, Zhen Zhou ${ }^{1}$ \\ ${ }^{1}$ Department of Shanghai Lung Cancer Center, ${ }^{2}$ Department of Pharmacy, Shanghai Chest Hospital, Shanghai Jiao Tong University, Shanghai \\ 200030, China \\ Contributions: (I) Conception and design: All authors; (II) Administrative support: None; (III) Provision of study materials or patients: Y Xu; (IV) \\ Collection and assembly of data: Y Xu, Y Pan; (V) Data analysis and interpretation: Y Xu, Y Pan; (VI) Manuscript writing: All authors; (VII) Final \\ approval of manuscript: All authors. \\ "These authors contributed equally to this work. \\ Correspondence to: Zhen Zhou. Department of Shanghai Lung Cancer Center, Shanghai Chest Hospital, Shanghai Jiao Tong University, No. 241 \\ Huaihai West Road, Shanghai 200030, China. Email: Drzhou1116@126.com.
}

Background: To investigate the effects of recombinant human thrombopoietin (rhTPO) and interleukin-2 (IL-2) on a basic gemcitabine (GEM) plus carboplatin (GC) treatment regimen in a murine lung carcinoma model.

Methods: Fifty nude mice with subcutaneous tumors derived from human lung cancer cells were divided into 5 groups, each comprised of 10 mice: A blank group (intraperitoneal injection of saline), a control group (GC) (intraperitoneal injections of GC), a rhTPO group (same as the control group plus subcutaneous injection of rhTPO), an IL-2 group (same as the control group plus subcutaneous injection of IL-2) and a rhTPO + IL-2 group (same as the rhTPO group plus subcutaneous injection of IL-2). Tumor development and histology as well as CD4+, phosphorylated-adenosine monophosphate-activated protein kinase (p-AMPK), phosphorylated-protein kinase B (p-AKT), phosphorylated-extracellular signal-regulated kinase (p-ERK), phosphorylated-phosphoinositide 3-kinase (p-pI3K) and GTPase RAS1 expression in tumor tissues were measured and blood analyses performed.

Results: Tumor sizes from all treated mice were significant smaller than the controls, as were the tumors of IL-2 plus GC treated mice compared to other treated groups. CD4+ expressing cells were increased in tumors after IL-2 and rhTPO treatment and the application of rhTPO significantly restored the blood platelet count. The expression of p-AMPK, p-AKT, p-ERK, p-pI3K and RAS1 in tumor cells were all significantly diminished after the addition of rhTPO and IL-2 to the GC regimen.

Conclusions: The supplementation of rhTPO and IL-2 to a GC regime effectively reduced tumor sizes and restored the platelet count in a human lung cancer mouse model.

Keywords: Recombinant human thrombopoietin (rhTPO); interleukin-2 (IL-2); gemcitabine (GEM); carboplatin; lung carcinoma; mouse model

Submitted May 09, 2019. Accepted for publication Sep 27, 2019.

doi: $10.21037 /$ jtd.2019.10.58

View this article at: http://dx.doi.org/10.21037/jtd.2019.10.58 


\section{Introduction}

Gemcitabine (GEM) is a new type of deoxycytidine analogue and a first-line anticancer drug that mainly acts on the $\mathrm{S}$ phase (DNA synthesis) of the cell cycle, but has no effects on the G2 and $M$ phases (1). According to previous research, a GEM plus carboplatin combination therapy (GC) can effectively treat advanced triple-negative breast cancer (TNBC) (2). Furthermore, GC has a certain curative effect on treatment failures of advanced breast cancer after anthracene nucleus and taxol administration. Also, combination therapy can effectively act on recurrent ovarian cancer (3) and as a second-line treatment for advanced nasopharyngeal carcinoma (4). However, therapy with GEM can cause thrombocytopenia (5), which may lead to cessation of the treatment. A previous clinical study reported that GC has the inevitable side effect of myelosuppression, which can lead to some patients having varying degrees of anemia, leukopenia and thrombocytopenia $(6,7)$. Therefore, recombinant human thrombopoietin (rhTPO) has recently been used as an adjuvant to chemotherapy in an attempt to relieve thrombocytopenia (8). rhTPO cannot accelerate platelet discharge from mature megakaryocytes, though it can act on progenitor cells of the incipient megakaryocytic series. As a result, rhTPO is used prophylactically to reduce the severity and duration of thrombocytopenia caused by carboplatin therapy (9). Interleukin 2 (IL-2) is a cytokine that promotes $\mathrm{CD} 8+\mathrm{T}$ cell and natural killer (NK) cell cytotoxicity as well as naive $\mathrm{CD} 4+\mathrm{T}$ cell differentiation into T helper-1 (Th1) and T helper-2 (Th2) cells (10). This agent has been investigated as mono or combination therapy with melatonin, TNF and beta-interferon for nonsmall cell lung carcinomas (NSCLC) (11-15). An imbalance of the IL-2/IL-2 receptor system in advanced NSCLC has also been reported (16).

In the present study, based on previous experiments, we established a NSCLC mouse model to study further the chemosensitivity and thrombocytopenia effects of rhTPO +IL-2 on NSLC treatment. We investigated whether the addition of rhTPO could increase the number of platelets in lung cancer and whether IL-2 could improve the immune system as well as enhance the inhibitory effect of chemotherapy drugs on tumor cells. For this study, we selected 5 related cancer signal pathway genes and evaluated whether the presence of rhTPO and IL-2 could regulate the chemotherapy sensitivity and platelet count reduction by influencing them.

\section{Methods}

\section{Cell culture and tumor formation}

A lung squamous carcinoma cell line (NCI-H520) was purchased from ATCC (HTB-182) and cultured in RPMI1640 medium supplemented with $10 \% \mathrm{FBS}$, $100 \mu \mathrm{g} / \mathrm{mL}$ streptomycin and $100 \mathrm{U} / \mathrm{mL}$ penicillin at $37^{\circ} \mathrm{C}$ in a $5 \% \mathrm{CO}_{2}$ humidified atmosphere. The culture medium was changed every 3 to 4 days depending on the status of the cells. After the cells reached a density of $1 \times 10^{7}$ cells per $40 \mathrm{~mL}$ flask, they were trypsinized and inoculated into the right anterior axillary side of a mouse $\left(1 \times 10^{7}\right.$ cells in $0.1 \mathrm{~mL}$ ). Tumors usually formed after 4 weeks and grew to $100-150 \mathrm{~mm}^{3}$. Then, they were grouped randomly for drug administration. Tumor volume was calculated using the following equation:

$\mathrm{V}=\left(\mathrm{a} \times \mathrm{b}^{2}\right) / 2$, where " $\mathrm{a}$ " equals tumor length and " $\mathrm{b}$ " equals tumor width.

\section{Two-animal administration method}

All procedures involving animals were performed in accordance with the ethical standards of the Guidelines for the Humane Treatment of Laboratory Animals (Ministry of Science and Technology of the People's Republic of China, Policy No. 2006 398). The Ethics Committee of Shanghai Chest Hospital approved the study (KS1871).

Seventy-five female nude mice (5-6 weeks old) were ordered from the SPF-level laboratory animal center. Fifty mice were eventually selected and randomly divided into 5 groups, with 10 mice in each group thus: (I) Blank group (normal saline group), intraperitoneal injection of saline; (II) Control group (GC), intraperitoneal injection of GEM $(120 \mathrm{mg} / \mathrm{kg})$ at D1 and D8, intraperitoneal injection of carboplatin $(30 \mathrm{mg} / \mathrm{kg})$ at D1, repeated every 3 weeks; (III) GC plus rhTPO group, same as the control group plus subcutaneous injection of $\mathrm{rhTPO}(50 \mu \mathrm{g} / \mathrm{kg} / \mathrm{day})$ at D2, D4, D6, and D9, repeated every 3 weeks; (IV) GC plus IL-2 group, same as the control group plus subcutaneous injection with IL-2 $(25 \mathrm{kU} / \mathrm{mL})$ from D1 to D9 (a total of $0.2 \mathrm{~mL}$ was injected 3 times per day), repeated every 3 weeks; and (V) GC plus rhTPO + IL-2 group: same as the IL-2 group plus subcutaneous injection of rhTPO (25 kU/mL) from D1 to D9 (a total of $0.2 \mathrm{~mL}$ was injected 3 times per day), repeated every 3 weeks (Figure 1). If any of the following situations occurred, the observations were stopped: tumor volume $>1,000 \mathrm{~mm}^{3}$, weight decline $>15 \%$, 


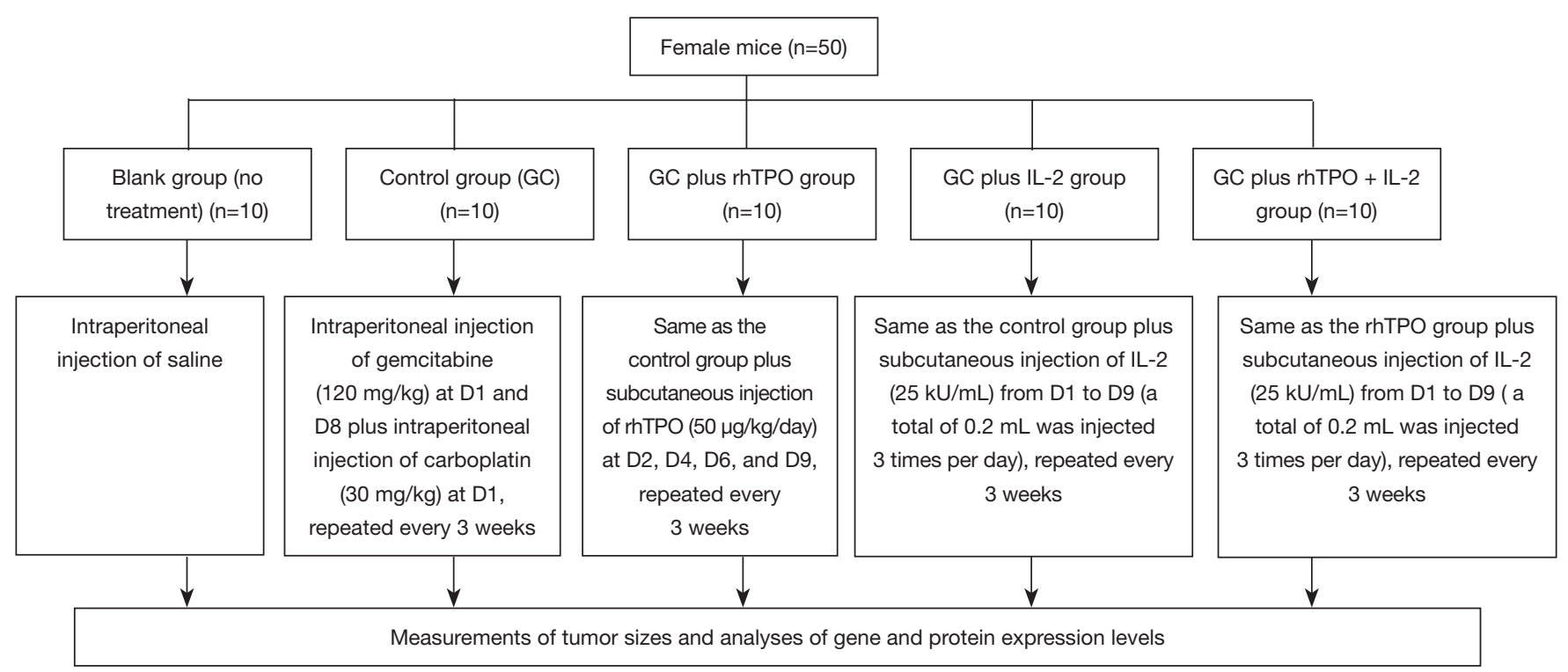

Figure 1 Flow chart of the present study. GC, gemcitabine plus carboplatin; rhTPO, recombinant human thrombopoietin.

active ulcer at the transplanted tumor site or abnormal behavior or anxiety of the mice.

\section{Observation indexes after tumor formation}

The tumor length and width were measured using vernier calipers every 3 days. The average tumor volume in each group was plotted as a tumor growth curve. Mouse weight was also measured. At D21 after tumor formation, $0.5 \mathrm{~mL}$ of mouse blood was sampled for analysis of the hemoglobin level, white blood cell, granulocyte and platelet counts. After observations, each mouse was anesthetized with ether and after corneal and pain reflexes were abolished, they were rapidly killed by cervical dislocation. Tumors were dissected for the measurement of their weights and specimens were immediately fixed in formalin or frozen $\left(-80{ }^{\circ} \mathrm{C}\right)$ for subsequent analysis. The inhibition rate (IR) was calculated using the following equation:

IR $(\%)=[1-($ tumor weight of treatment group/tumor weight of control group) $] \times 100 \%$

\section{Analysis of gene and protein expression levels in mouse tumor tissue (Western blot)}

Tumor tissue fragments were homogenized and after $30 \mathrm{~min}$ lysis in lysis buffer on ice, the lysate was transferred into $1.5 \mathrm{~mL}$ tubes and centrifuged for $5 \mathrm{~min}$ at 12,000 rpm at $4{ }^{\circ} \mathrm{C}$. The extracted protein supernatant was mixed with
$5 \times$ volume of loading buffer and boiled in a water bath for $10 \mathrm{~min}$. The denatured samples were cooled to room temperature and subjected to SDS-PAGE electrophoresis. The PVDF membranes were incubated with primary antibodies including p-AMPK 1:10,000 (50081; Cell Signaling Technology, Inc., US), $\beta$-actin 1:200 (BM0627; BOSTER Biological Technology Co. Ltd, Wuhan, China), p-AKT 1:2000 (4060; Cell Signaling Technology, Inc., US), p-ERK 1:2,000 (4370; Cell Signaling Technology, Inc., US), p-pI3K 1:800 (Bs-6417R; BIOSS Biological Technology Co. Ltd, Beijing, China) and RAS 1:800 (Bs-1515R; BIOSS Biological Technology Co. Ltd, Beijing, China). Then membranes were incubated with HRP labelled secondary antibody (1:50,000 dilution, BA1051 and BA1054; BOSTER Biological Technology Co. Ltd, Wuhan, China).

\section{Immunohistochemistry}

The specimens were dehydrated in sequential concentrations of alcohol. Clarifier was used to facilitate paraffin penetration into the tissues. The clarified tissue fragments were successively wax-dipped and then sectioned. After sectioning, tissues were incubation with primary antibody (CD34, 14486-1-AP, 1:200) and HPR labelled secondary IgG. Freshly prepared DAB developing solution was dropped onto each tissue slice before they were observed under a microscope. Tissues were subsequently re-stained with Harris hematoxylin for $30 \mathrm{~s}$ to $1 \mathrm{~min}$ and differentiated 
by $1 \%$ hydrochloric acid in alcohol solution after washing in distilled water. Then, DI water or PBS was used to wash out the blue coloration. After dehydration and mounting, images were acquired using a microscope (Nikon E100).

\section{HE staining}

Tissue slices were placed in Harris hematoxylin solution for 5-7 min after sectioning, and distilled water was used to wash out the excess blue coloration. The slices were then differentiated by exposure to $1 \%$ hydrochloric acid in alcohol solution for 2-5 s, and again distilled water used to wash away excessive blue dye. Tissue slices were then placed in $1 \%$ eosin dye solution for $2 \mathrm{~min}$, and then washed for $30 \mathrm{~s}$. Then, each tissue slice was dehydrated using absolute ethyl alcohol, clarified by xylene and mounted in neutral balsam after air-drying. Finally, they were observed under a microscope (Nikon E100). The nuclei were stained blue and the cytoplasm, muscle fibers, collagen fibers, and red blood cells stained to varying degrees of red.

\section{Statistical analysis}

All the statistical analysis was performed using SPSS Statistics for Windows (ver. 17.0, SPSS Inc., US). Data are presented as means \pm SD. Data sets were compared using a chi-squared analysis for categorical variables and two-tailed Student's $t$-tests for continuous variables. ANOVA and a Mann-Whitney test were used for multiple comparisons, with a post-hoc of Boniferroni correction applied. A P value $<0.05$ was considered to be statistically significant.

\section{Results}

\section{Tumor formation}

The tumor volumes in the blank group $(n=10)$ were the first to reach $1,000 \mathrm{~mm}^{3}$, followed by the control $(\mathrm{n}=10)$, GC plus rhTPO (n=10), GC plus rhTPO+IL-2 ( $\mathrm{n}=10)$ and GC plus IL-2 ( $n=10)$ groups. Compared to the blank group, the GC treatment regimen exhibited a tumor inhibitory effect which was significantly enhanced by the addition of IL-2 (GC plus IL-2 and GC plus rhTPO and IL-2) (Figure 2, Table 1).

\section{Blood routine measurements: variations in white blood cell, neutrophils, granulocytes and lymphocytes counts}

All GC treated mice showed reduced white blood cell and lymphocyte counts as well as platelet counts. Addition of IL-2 to the GC regimen produced an obvious additional reduction in the effect on white blood cell and lymphocyte counts after D22. rhTPO as mono and combination therapy enhanced the number of platelets compared to the untreated control mice (Table 2).

\section{HE staining and IHC of CD34+ expressing cells}

Tumor tissue was collected to determine its histological morphology. CD34 expression levels were observed using CD34 antibodies to analyze the proportion of new blood vessels in the tumor tissue.

HE staining: normally, platelets have a double convex shape but adopt an irregular shape after a stimulus. Their size was about $2-4 \mu \mathrm{m}$ in diameter, $0.2-1.5 \mu \mathrm{m}$ thickness and had an average volume of $7 \mu^{3}$. There were no nuclei in platelets with light blue cytoplasm and yellow granules. The addition of rhTPO and IL-2 to GC therapy increased the number of platelets (Figure $3 A$ ). In addition, tissue sections after supplementary treatment with rhTPO and IL-2 to the GC regimen revealed significant increases in CD34+ expressing cells (Figure 3B).

\section{Expression levels of target genes in each signal pathway after different treatments}

From the western blot results, compared to the control group, the GC plus IL-2 group exhibited small declines in the expression level of p-AKT, p-ERK, p-pI3K, p-AMPK and RAS. The decreases, however, were not as obvious as in the GC plus rhTPO and GC plus rhTPO+IL-2 groups which suggested that rhTPO had a significant curative effect in combination with GC and IL-2 (Figure 4).

\section{Discussion}

In the present study, NCI-H520 cells were subcutaneously injected into the right anterior axillary side of nude mice to form tumors within 4 weeks. A combination chemotherapy (GC) was administered and led to significant tumor size reductions, but also produced the known side effects of leukopenia and thrombocytopenia. rhTPO could effectively increase the number of platelets under the GC regimen to almost double the numbers in untreated controls (Table 2), whereas the addition of IL-2 to the GC regimen produced further significant reductions in tumor sizes (Table 1). Our study also revealed that a combination of rhTPO and IL-2 
A

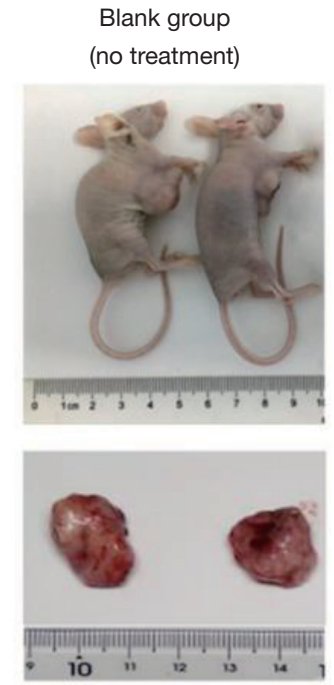

\section{GC plus IL-2 group}
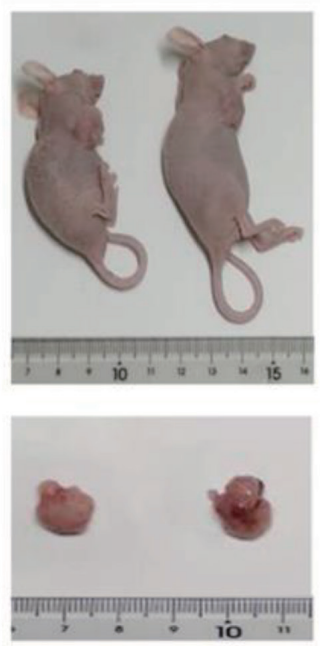

Control group (GC)
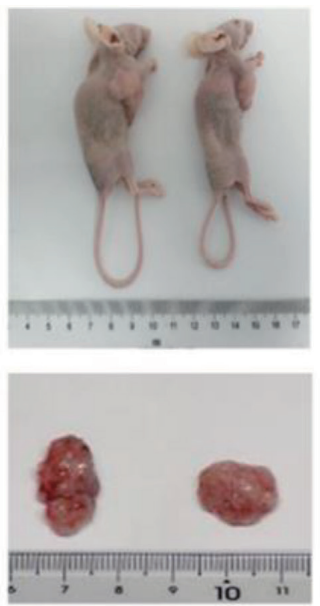

GC plus rhTPO + IL-2 group
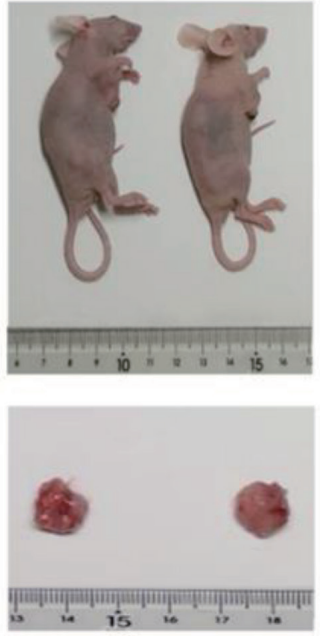

B

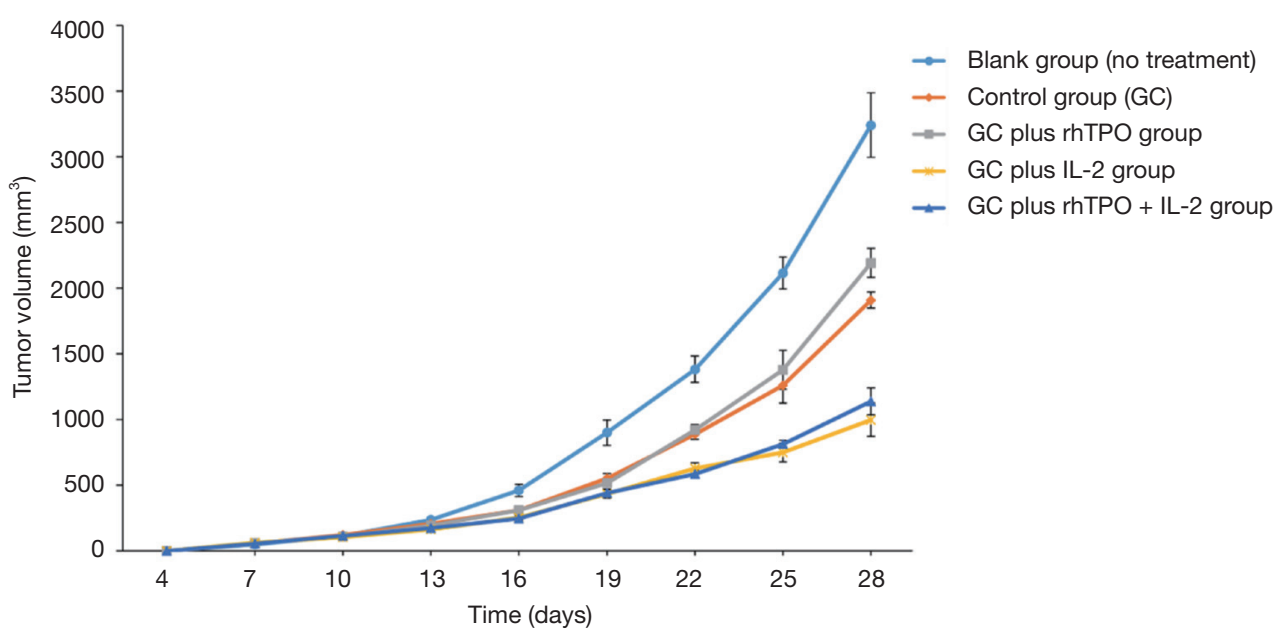

Figure 2 Tumor growth in the indicated mice. GC, gemcitabine plus carboplatin; rhTPO, recombinant human thrombopoietin. 
Table 1 Comparison of tumor volumes (22 days) in the different groups

\begin{tabular}{lcc}
\hline Treatment regimen & Volume of tumor $\left(\mathrm{mm}^{3}, 22\right.$ days $)$ & $P$ value \\
\hline Blank group (no treatment) $(\mathrm{n}=10)$ & $1,381.8 \pm 100.9^{\mathrm{a}}$ & $<0.001$ \\
Control group $(\mathrm{GC})(\mathrm{n}=10)$ & $921.0 \pm 39.3^{\mathrm{b}}$ \\
GC plus rhTPO group $(\mathrm{n}=10)$ & $887.1 \pm 39.5^{\mathrm{b}}$ \\
GC plus IL-2 group $(\mathrm{n}=10)$ & $584.1 \pm 31.5^{\mathrm{c}}$ \\
GC plus rhTPO + IL-2 group $(\mathrm{n}=10)$ & $628.6 \pm 43.0^{\mathrm{c}}$ \\
\hline
\end{tabular}

Different upper-case letters $(a, b, c)$ denote a significant difference at $\mathrm{P}<0.05$ between the different treatment groups. GC, gemcitabine plus carboplatin; rhTPO, recombinant human thrombopoietin.

Table 2 Blood routine indices in indicated groups

\begin{tabular}{|c|c|c|c|c|c|c|}
\hline Measurements & $\begin{array}{l}\text { Blank group (no } \\
\text { treatment) }(n=10)\end{array}$ & $\begin{array}{l}\text { Control group } \\
(\mathrm{GC})(\mathrm{n}=10)\end{array}$ & $\begin{array}{l}\text { GC plus rhTPO } \\
\text { group }(n=10)\end{array}$ & $\begin{array}{l}\text { GC plus IL-2 } \\
\text { group }(n=10)\end{array}$ & $\begin{array}{l}\text { GC plus rhTPO + } \\
\text { IL-2 group }(n=10)\end{array}$ & $P$ value \\
\hline White blood cells $\left(\times 10^{9} / \mathrm{L}\right)$ & $16.5 \pm 4.4^{\mathrm{a}}$ & $11.1 \pm 1.1^{\mathrm{b}}$ & $9.8 \pm 0.8 b$ & $5.8 \pm 1.4^{\mathrm{c}}$ & $6.3 \pm 1.5^{c}$ & $<0.001$ \\
\hline Monocytes (×109/L) & $0.9 \pm 0.3^{\mathrm{a}}$ & $0.7 \pm 0.2^{\mathrm{ab}}$ & $0.4 \pm 0.3^{\mathrm{bc}}$ & $0.3 \pm 0.2^{c}$ & $0.2 \pm 0.1^{c}$ & $<0.001$ \\
\hline Granulocytes (×10/L) & $5.1 \pm 2.1^{\mathrm{a}}$ & $5.2 \pm 1.4^{\mathrm{a}}$ & $3.5 \pm 1.9 \mathrm{a}^{\mathrm{bc}}$ & $2.6 \pm 0.9^{b c}$ & $1.6 \pm 0.8^{c}$ & $<0.001$ \\
\hline Monocyte (\%) & $5.7 \pm 2.8$ & $6.3 \pm 1.6$ & $4.6 \pm 2.4$ & $5.7 \pm 2.3$ & $3.7 \pm 1.5$ & 0.076 \\
\hline Granulocyte (\%) & $33.4 \pm 17.4^{\mathrm{ab}}$ & $46.5 \pm 11.2^{\mathrm{a}}$ & $35.5 \pm 18.8^{\mathrm{ab}}$ & $43.8 \pm 10.4^{\mathrm{ab}}$ & $26.1 \pm 10.6^{b}$ & 0.017 \\
\hline Red blood cell (×10²/L) & $9.3 \pm 0.6$ & $10.3 \pm 2.3$ & $9.8 \pm 0.9$ & $9.1 \pm 1.9$ & $9.8 \pm 0.4$ & 0.373 \\
\hline Mean corpuscular hemoglobin (pg) & $14.6 \pm 1.8$ & $14.4 \pm 1.4$ & $13.9 \pm 0.4$ & $14.2 \pm 1.8$ & $15.9 \pm 2.0$ & 0.067 \\
\hline $\begin{array}{l}\text { Mean corpuscular-hemoglobin } \\
\text { concentration }(\mathrm{g} / \mathrm{L})\end{array}$ & $344.0 \pm 102.8$ & $342.8 \pm 89.0$ & $288.7 \pm 9.0$ & $291.8 \pm 29.3$ & $306.7 \pm 21.4$ & 0.140 \\
\hline $\begin{array}{l}\text { Red cell distribution width } \\
\text { variation coefficient (\%) }\end{array}$ & $19.3 \pm 3.9^{\mathrm{a}}$ & $20.1 \pm 4.9^{\mathrm{a}}$ & $16.4 \pm 1.3^{\mathrm{ab}}$ & $19.1 \pm 3.3^{\mathrm{a}}$ & $14.0 \pm 2.0^{b}$ & 0.001 \\
\hline Platelets $\left(\times 10^{9} / \mathrm{L}\right)$ & $897.5 \pm 515.7^{\mathrm{abc}}$ & $758.0 \pm 511.0^{\mathrm{bc}}$ & $1,406.0 \pm 481.3^{\mathrm{a}}$ & $478.2 \pm 182.8^{c}$ & $1,147.2 \pm 352.8^{\mathrm{ab}}$ & $<0.001$ \\
\hline Mean platelet volume (fl) & $5.9 \pm 0.8$ & $6.1 \pm 0.8$ & $6.6 \pm 0.4$ & $6.0 \pm 0.5$ & $5.9 \pm 0.9$ & 0.167 \\
\hline Platelet distribution width (\%) & $16.9 \pm 0.4$ & $16.6 \pm 0.3$ & $16.8 \pm 0.4$ & $16.8 \pm 0.9$ & $16.5 \pm 0.6$ & 0.500 \\
\hline
\end{tabular}

Different uppercase letters $(a, b, c)$ denote a significant difference at $\mathrm{P}<0.05$ between the treatment groups. GC, gemcitabine plus carboplatin; rhTPO, recombinant human thrombopoietin.

can effectively promote proliferation of CD34+ stem cells (Figure 2B). rhTPO as a stimulating factor for CD34+ cell development has been described in previous studies (17-20) and IL-2 in combination with other cytokines also stimulates CD34+ cell proliferation (21), but research on IL-2 has mainly focused on its function in activating natural killer (NK) cells (22-25). Reportedly, treatment with exogenous IL-2 can facilitate immunity of cells and increase the sensitivity of lung cancer to chemotherapy (26). After allogeneic hematopoietic cell transplantation, 
A

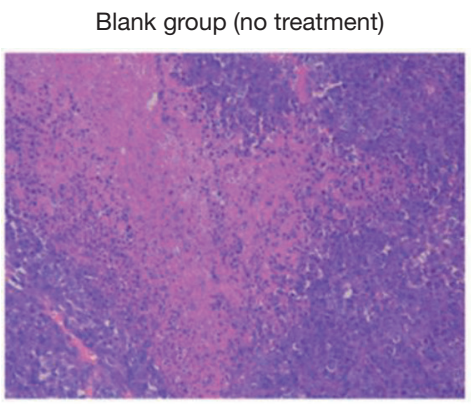

GC plus IL-2 group

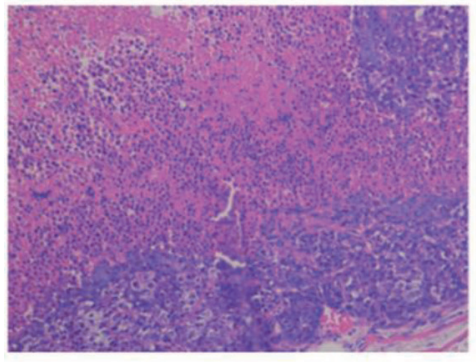

B

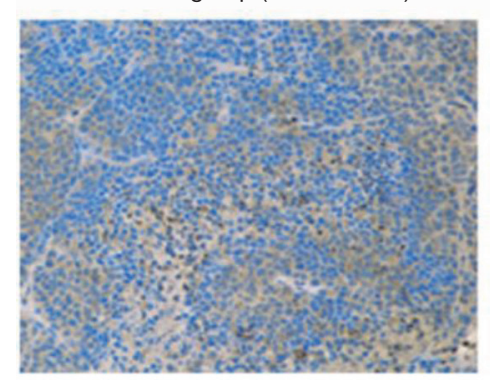

GC plus IL-2 group

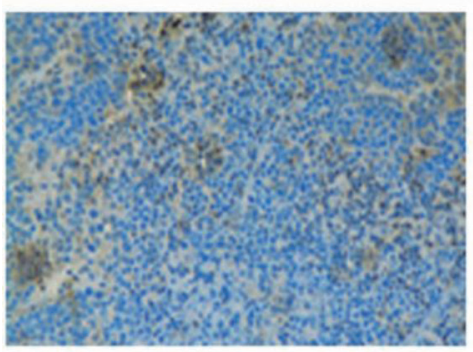

Control group (GC)

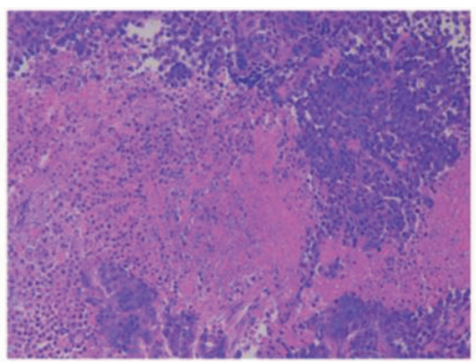

GC plus rhTPO + IL-2 group

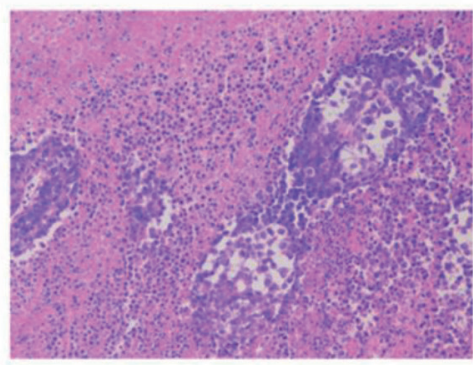

Control group (GC)

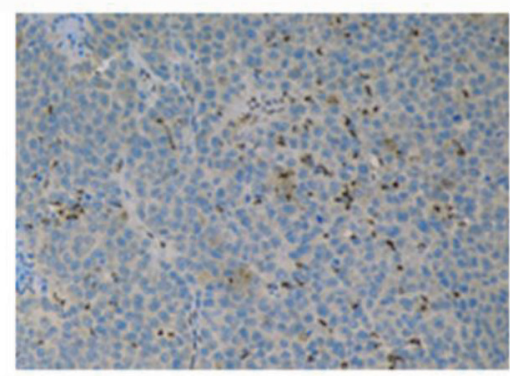

GC plus rhTPO + IL-2 group

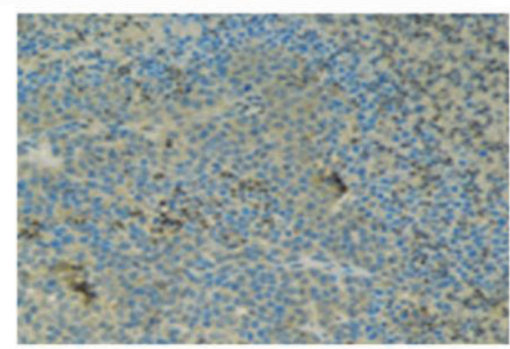

GC plus rhTPO group

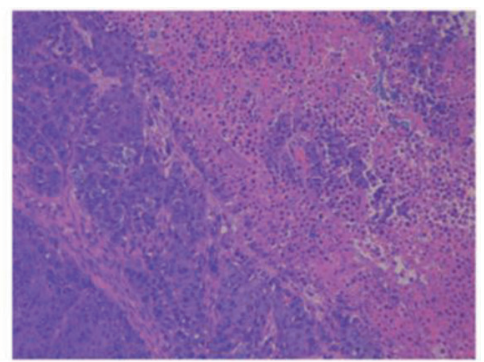

GC plus rhTPO group

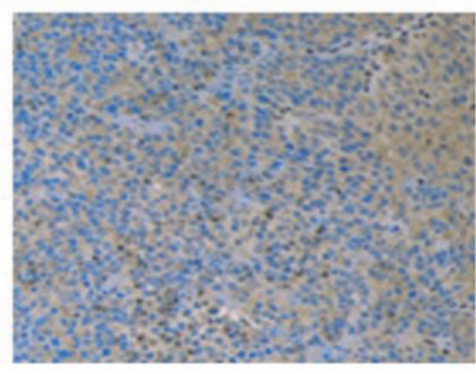

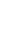

Figure 3 (A) HE staining of tumor tissues, (B) staining (brown) of CD34+ expressing cells in tumor tissues (Magnification $\times 200)$. GC, gemcitabine plus carboplatin; rhTPO, recombinant human thrombopoietin.

treatment of IL-2 and donor lymphocytes with chemotherapeutic agents can postpone the occurrence of acute leukemia (27). Our results underlined the antitumor effect of IL-2, since the addition of IL-2 to CG treatment regimens effectively further reduced tumor growth (Table 1). Remarkably, the Treg cell defects that strongly promote autoimmune responses appeared to be restored by exogenous IL-2 administered at low doses, both in mice $(28,29)$ and humans $(30)$. The doses of IL-2 used in the studies were as follows: mice were injected intraperitoneally with $2.5 \times 10^{4}$ IU/day of recombinant human (rh) IL-2 (31) or $1-2.5 \mu \mathrm{g} /$ day of recombinant mouse (rm) IL-2 (32); 
A

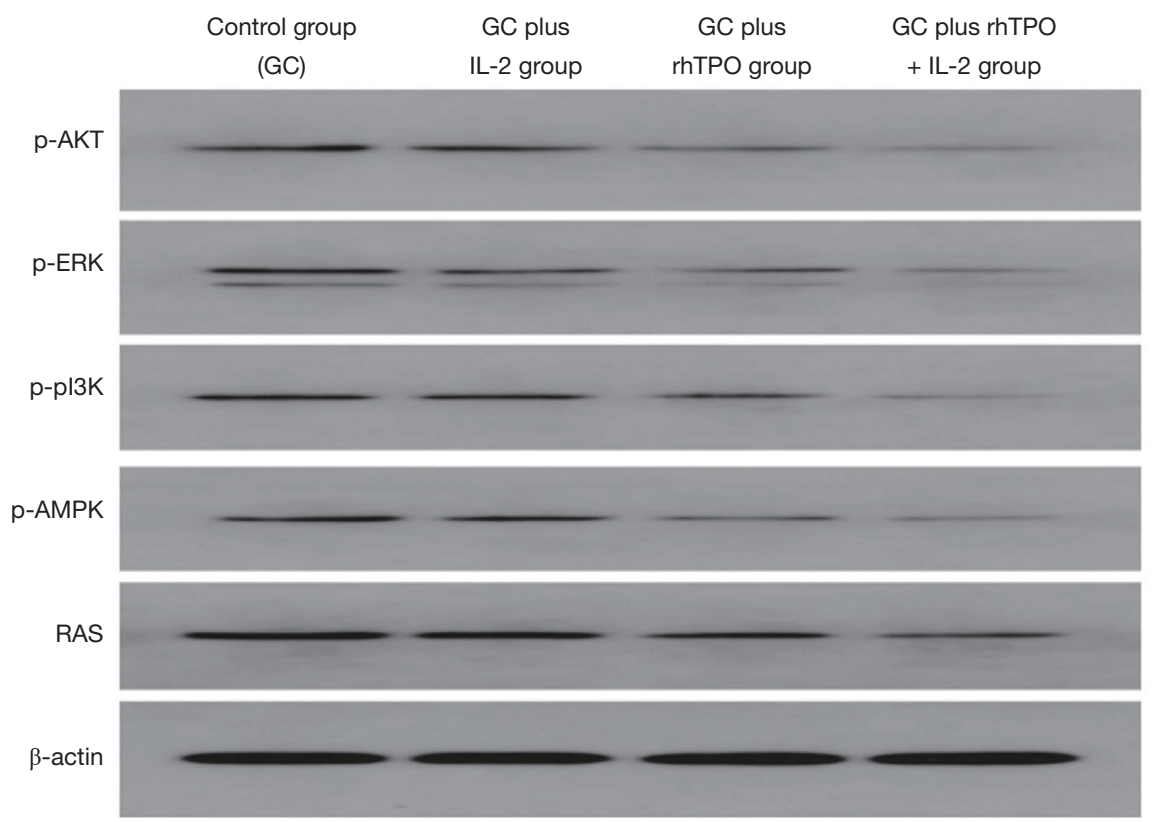

B

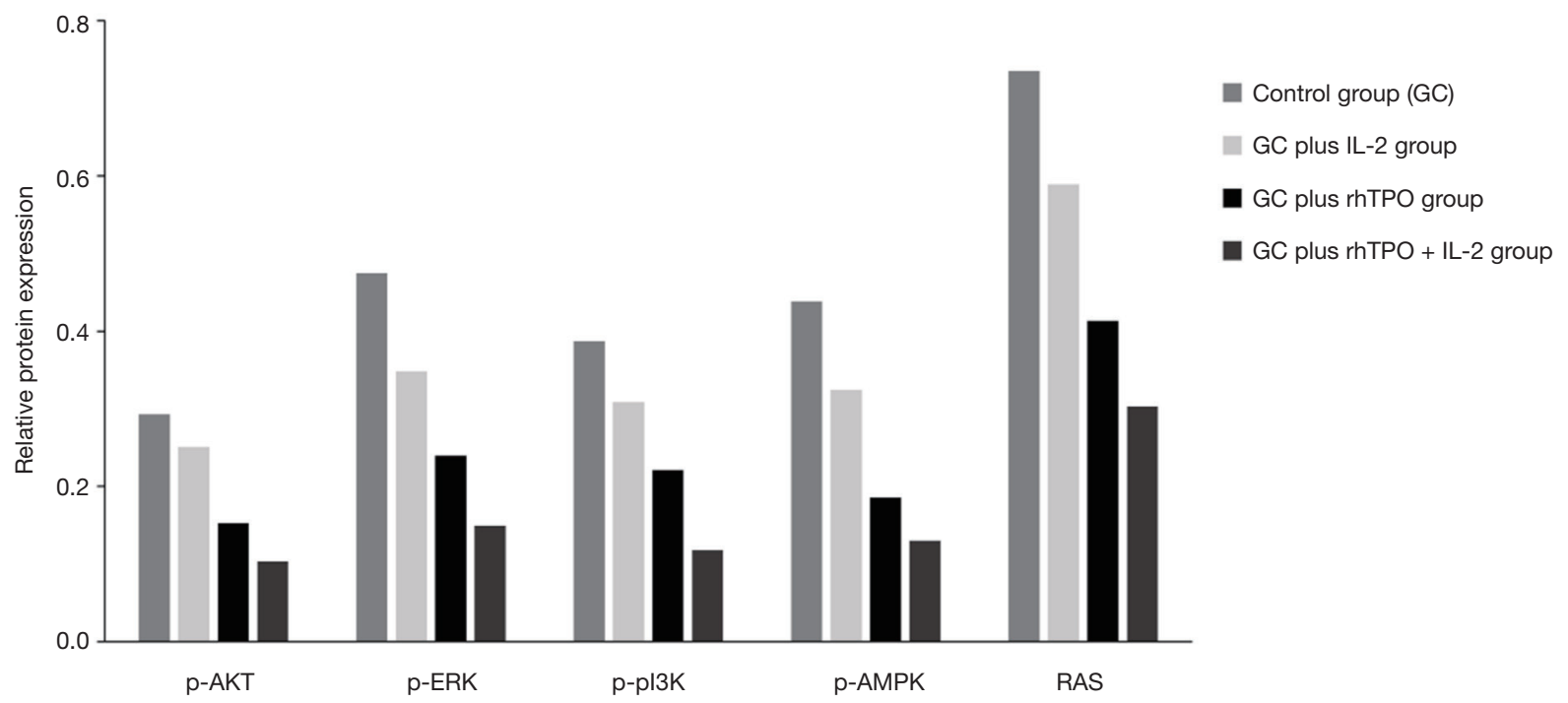

Figure 4 Western blot analysis of p-AKT, p-ERK, p-p13k, p-AMPK and RAS in the indicated mice. (A) Representative western blot image, (B) graph indicating the mean of 3 independent western blot analyses. GC, gemcitabine plus carboplatin; rhTPO, recombinant human thrombopoietin; p-AKT, phosphorylated-protein kinase B; p-ERK, phosphorylated-extracellular signal-regulated kinase; p-p13k, phosphorylated-phosphoinositide 3-kinase; p-AMPK, phosphorylated-adenosine monophosphate-activated protein kinase.

and humans were administered subcutaneously (sc) with $0.33 \times 10^{6}-4.5 \times 10^{6} \mathrm{IU} /$ day $(33)$. In our study, we used recombinant human (rh) IL-2 at a dose of $2.5 \times 10^{4} \mathrm{U} / \mathrm{mL}$, 3 times per day in a total volume of $0.2 \mathrm{~mL}\left(5 \times 10^{3} \mathrm{U} /\right.$ day $)$, which is low dose IL-2 administration. However, as an unexpected effect, IL-2 also reduced the number of white blood cells and lymphocytes, a finding which has been reported in a previous study. In the latter study, IL-2 decreased the numbers of peripheral lymphocytes by $93 \%$ within $24 \mathrm{~h}$ of therapy initiation, which was accompanied by lymphocytosis rebound 4 days after treatment (34).

A domestic prospective study (35) described MT (malignant tumor) patients who accepted rhTPO treatment based on chemotherapy for just 1 week to evaluate platelet 
levels, life quality, transfusion rate and antitumor effects. The results showed increased platelet levels, reduced transfusion rates and improved life quality after rhTPO treatment. In our study, rhTPO was shown to improve the release of platelets and aggregation of CD34+ cells. In addition, the results revealed that a combination of rhTPO and IL-2 can effectively inhibit the signaling pathways of p-AKT, p-ERK, p-pI3K, p-AMPK and RAS, which can improve thrombocytopenia, anemia and the harvest of CD34+ by using GC therapy.

However, one limitation of our study is it was based on a mouse model and we did not measure the toxic effect of different doses. In the future, apart from blood routine measurements of leukocytes, variations in platelet numbers and anemia after GC treatment of mice, it will be necessary to monitor other adverse effects such as depilation or vomiting.

\section{Conclusions}

Addition of rhTPO + IL2 to a GC basic treatment regimen can significantly inhibit thrombocytopenia after malignant tumor chemotherapy and can effectively decrease tumor formation and promote recovery of platelet levels by inducing chemotherapy sensitivity to NSCLCs.

\section{Acknowledgments}

The authors would like to thank Shenyang Sunshine Pharmaceuticals CO., Ltd for their assistance with technology support.

Funding: The study was supported by Collaborative Innovation Center for Translational Medicine at Shanghai Jiao Tong University School of Medicine (Grant number TM201610), Clinical Research Plan of SHDC (Grant number 16CR3102B) and the Shenyang 3S BIO TCP young and middle-aged scientist research fund. The funder had no role in the design of the study or collection, analysis and interpretation of data, or in the writing of the manuscript.

\section{Footnote}

Conflicts of Interest: The authors have no conflicts of interest to declare.

Ethical Statement: The authors are accountable for all aspects of the work in ensuring that questions related to the accuracy or integrity of any part of the work are appropriately investigated and resolved. All procedures involving animals were performed in accordance with the ethical standards of the Guidelines for the Humane Treatment of Laboratory Animals (Ministry of Science and Technology of the People's Republic of China, Policy No. 2006 398). The Ethics Committee of Shanghai Chest Hospital approved the study (KS1871).

\section{References}

1. Koh SB, Courtin A, Boyce RJ, et al. CHK1 Inhibition Synergizes with Gemcitabine Initially by Destabilizing the DNA Replication Apparatus. Cancer Res 2015;75:3583-95.

2. Maisano R, Zavettieri M, Azzarello D, et al. Carboplatin and gemcitabine combination in metastatic triple-negative anthracycline- and taxane-pretreated breast cancer patients: a phase II study. J Chemother 2011;23:40-3.

3. Le TN, Harvey RE, Kim CK, et al. A retrospective evaluation of activity of gemcitabine/platinum regimens in the treatment of recurrent ovarian cancer. Gynecol Oncol Res Pract 2017;4:16.

4. Lim AM, Corry J, Collins M, et al. A phase II study of induction carboplatin and gemcitabine followed by chemoradiotherapy for the treatment of locally advanced nasopharyngeal carcinoma. Oral Oncol 2013;49:468-74.

5. Winer ES, Safran H, Karaszewska B, et al. Eltrombopag for thrombocytopenia in patients with advanced solid tumors receiving gemcitabine-based chemotherapy: a randomized, placebo-controlled phase 2 study. Int J Hematol 2017;106:765-76.

6. Chisaki Y, Terada T, Yano Y. Population Pharmacodynamic Model for Bayesian Prediction of Myelosuppression Profiles Based on Routine Clinical Data after Gemcitabine and Carboplatin Treatment. Pharmacology 2016;98:284-93.

7. Lund B, Hansen OP, Neijt JP, et al. Phase II study of gemcitabine in previously platinum-treated ovarian cancer patients. Anticancer Drugs 1995;6 Suppl 6:61-2.

8. Tang G, Wang XM, Meng JX, et al. Efficacy of Recombinant Human Thrombopoietin and Recombinant Human Interleukin 11 for Treatment of Chemotherapy Indu-ced Thrombocytopenia in Acute Myeloid Leukaemia Patients. Zhongguo Shi Yan Xue Ye Xue Za Zhi 2018;26:234-8.

9. $\mathrm{Xu} \mathrm{YH,} \mathrm{Cheng} \mathrm{BJ,} \mathrm{Lu} \mathrm{S,} \mathrm{et} \mathrm{al.} \mathrm{Short-term} \mathrm{intermittent}$ prophylactic administration of recombinant human thrombopoietin attenuates chemotherapy-induced 
thrombocytopenia in lung cancer patients. Zhonghua Zhong Liu Za Zhi 2011;33:395-9.

10. Jiang T, Zhou C, Ren S. Role of IL-2 in cancer immunotherapy. Oncoimmunology 2016;5:e1163462.

11. Ardizzoni A, Bonavia M, Viale M, et al. Biologic and clinical effects of continuous infusion interleukin-2 in patients with non-small cell lung cancer. Cancer 1994 73:1353-60.

12. Chen YM, Yang WK, Whang-Peng J, et al. Restoration of the immunocompetence by IL-2 activation and TCR-CD3 engagement of the in vivo anergized tumor-specific CTL from lung cancer patients. J Immunother 1997;20:354-64.

13. Lissoni P, Meregalli S, Fossati V, et al. A randomized study of immunotherapy with low-dose subcutaneous interleukin-2 plus melatonin vs chemotherapy with cisplatin and etoposide as first-line therapy for advanced non-small cell lung cancer. Tumori 1994;80:464-7.

14. Schiller JH, Morgan-Ihrig C, Levitt ML. Concomitant administration of interleukin-2 plus tumor necrosis factor in advanced non-small cell lung cancer. Am J Clin Oncol 1995;18:47-51.

15. Tester WJ, Kim KM, Krigel RL, et al. A randomized Phase II study of interleukin-2 with and without betainterferon for patients with advanced non-small cell lung cancer: an Eastern Cooperative Oncology Group study (PZ586). Lung Cancer 1999;25:199-206.

16. De Vita F, Turitto G, di Grazia M, et al. Analysis of interleukin-2/interleukin-2 receptor system in advanced non-small-cell lung cancer. Tumori 1998;84:33-8.

17. Linker C, Anderlini P, Herzig R, et al. Recombinant human thrombopoietin augments mobilization of peripheral blood progenitor cells for autologous transplantation. Biol Blood Marrow Transplant 2003;9:405-13.

18. Murray LJ, Luens KM, Estrada MF, et al. Thrombopoietin mobilizes CD34+ cell subsets into peripheral blood and expands multilineage progenitors in bone marrow of cancer patients with normal hematopoiesis. Exp Hematol 1998;26:207-16.

19. Ji L, Xing PN, Wei XC, et al. Expansion in vitro and cytotoxicity of dendritic cells from patients with chronic myeloid leukemia. Zhongguo Shi Yan Xue Ye Xue Za Zhi 2005;13:198-204.

20. Wang G, Chen W, Wu Y, et al. Recombinant human thrombopoietin improves the efficacy of intermediate-dose cyclophosphamide plus granulocyte colony-stimulating factor in mobilizing peripheral blood stem cells in patients with multiple myeloma: A cohort study. Medicine
(Baltimore) 2017;96:e9302.

21. Wei Y, Huang Y, Zhang Y, et al. Ex vivo expansion of CD34+ and T and NK cells from umbilical cord blood for leukemic BALB/C nude mouse transplantation. Int J Hematol 2008;87:217-24.

22. Lehmann C, Zeis M, Uharek L. Activation of natural killer cells with interleukin 2 (IL-2) and IL-12 increases perforin binding and subsequent lysis of tumour cells. Br J Haematol 2001;114:660-5.

23. Deehan DJ, Heys SD, Ashby J, et al. Interleukin-2 (IL2) augments host cellular immune reactivity in the perioperative period in patients with malignant disease. Eur J Surg Oncol 1995;21:16-22.

24. Richards JM. Therapeutic uses of interleukin-2 and lymphokine-activated killer (LAK) cells. Blood Rev 1989;3:110-9.

25. Henney CS, Kuribayashi K, Kern DE, et al. Interleukin-2 augments natural killer cell activity. Nature 1981;291:335-8.

26. Bosly A, Guillaume T, Brice P, et al. Effects of escalating doses of recombinant human interleukin-2 in correcting functional T-cell defects following autologous bone marrow transplantation for lymphomas and solid tumors. Exp Hematol 1992;20:962-8.

27. Inamoto Y, Fefer A, Sandmaier BM, et al. A phase I/II study of chemotherapy followed by donor lymphocyte infusion plus interleukin-2 for relapsed acute leukemia after allogeneic hematopoietic cell transplantation. Biol Blood Marrow Transplant 2011;17:1308-15.

28. Grinberg-Bleyer Y, Baeyens A, You S, et al. IL-2 reverses established type 1 diabetes in NOD mice by a local effect on pancreatic regulatory T cells. The Journal of Experimental Medicine 2010;207:1871-8.

29. Zhang H, Chua KS, Guimond M, et al. Lymphopenia and interleukin-2 therapy alter homeostasis of CD4+CD25+ regulatory T cells. Nat Med 2005;11:1238-43.

30. Matsuoka K, Koreth J, Kim HT, et al. Low-dose interleukin-2 therapy restores regulatory $\mathrm{T}$ cell homeostasis in patients with chronic graft-versus-host disease. Sci Transl Med 2013;5:179ra43.

31. Dinh TN, Kyaw TS, Kanellakis P, et al. Cytokine therapy with interleukin-2/anti-interleukin-2 monoclonal antibody complexes expands CD4+CD25+Foxp3+ regulatory T cells and attenuates development and progression of atherosclerosis. Circulation 2012;126:1256-66.

32. Wilson MS, Pesce JT, Ramalingam TR, et al. Suppression of murine allergic airway disease by IL-2:anti-IL-2 monoclonal antibody-induced regulatory $\mathrm{T}$ cells. J 
Immunol 2008;181:6942-54.

33. Koreth J, Matsuoka K, Kim HT, et al. Interleukin-2 and regulatory $\mathrm{T}$ cells in graft-versus-host disease. $\mathrm{N}$ Engl J Med 2011;365:2055-66.

34. MacFarlane MP, Yang JC, Guleria AS, et al. The hematologic toxicity of interleukin-2 in patients with

Cite this article as: $\mathrm{Xu} Y, \mathrm{Pan} \mathrm{Y}, \mathrm{Zhou} \mathrm{Z}$. Recombinant human thrombopoietin combined with interleukin-2 improves the effects of chemosensitivity and thrombocytopenia on a basic gemcitabine and carboplatin combination therapy for nonsmall cell lung cancer in a nude mouse model. J Thorac Dis 2019;11(11):4671-4681. doi: 10.21037/jtd.2019.10.58 metastatic melanoma and renal cell carcinoma. Cancer 1995;75:1030-7.

35. Bai CM, Zou XY, Zhao YQ, et al. The clinical study of recombinant human thrombopoietin in the treatment of chemotherapy-induced severe thrombocytopenia. Zhonghua Yi Xue Za Zhi 2004;84:397-400. 